\title{
The effect of 4-hexylresorcinol on xenograft degradation in a rat calvarial defect model
}

\author{
Yei-Jin Kang ${ }^{1}$, Ji-Eun Noh', Myung-Jin Lee ${ }^{2}$, Weon-Sik Chae ${ }^{3}$, Si Young Lee ${ }^{1}$ and Seong-Gon Kim ${ }^{1 *}$ (D)
}

\begin{abstract}
Background: The objective of this study was to evaluate xenograft degradation velocity when treated with 4-hexylresorcinol (4HR).

Methods: The scapula of a cow was purchased from a local grocery, and discs (diameter $8 \mathrm{~mm}$, thickness $1 \mathrm{~mm}$ ) were prepared by trephine bur. Discs treated with $4 \mathrm{HR}$ were used as the experimental group. Untreated discs were used as the control. X-ray diffraction (XRD), Fourier transform infrared spectroscopy (FT-IR), antibacterial test, endotoxin test, and scanning electron microscopy (SEM) were performed on the discs. In vivo degradation was evaluated by the rat calvarial defect model.

Results: The XRD and FT-IR results demonstrated successful incorporation of 4HR into the bovine bone. The experimental disc showed antibacterial properties. The endotoxin test yielded results below the level of endotoxin contamination. In the SEM exam, the surface of the experimental group showed needle-shaped crystal and spreading of RAW264.7 cells. In the animal experiments, the amount of residual graft was significantly smaller in the experimental group compared to the control group $(P=0.003)$.

Conclusions: In this study, 4HR was successfully incorporated into bovine bone, and 4HR-incorporated bovine bone had antibacterial properties. In vivo experiments demonstrated that $4 \mathrm{HR}$-incorporated bovine bone showed more rapid degradation than untreated bovine bone.
\end{abstract}

Keywords: 4-Hexylresorcinol, Bovine, Bone graft, Degradation

\section{Background}

Many types of graft materials have been used for the reconstruction of the maxillofacial region [1]. Although autogenous bone grafting is the gold standard, the amount of available bone is limited, and donor site morbidity has been reported [2]. Xenografts are widely used in the dental field, and many of them are bovineoriginated xenografts [3]. For the successful bone graft procedure, timely degradation of the graft is essential for new bone regeneration. However, most xenografts and allografts have poor biodegradability $[4,5]$. If the graft is not degraded in a timely manner, the space occupied by the graft cannot be replaced by newly regenerated bone.

\footnotetext{
* Correspondence: kimsg@gwnu.ac.kr

${ }^{1}$ Department of Oral Microbiology, College of Dentistry, Gangneung-Wonju National University, 7 Jukhyun-gil, Gangneung 25457, Republic of Korea Full list of author information is available at the end of the article
}

4-Hexylresorcinol (4HR) is a family of resorcinolic lipids [6]. 4HR is a well-known antiseptic [7] and reduces the melanosis of food [8]. Therefore, it has been used for oral gargling [7], for treatment of sore throat [9], or as a food ingredient [7]. Recently, its molecular mechanism was unveiled in a cancer cell study. 4HR suppresses calcium oscillation [10] and the nuclear factor-kB (NF-kB) pathway [11]. 4HR can induce cellular differentiation via increasing the expression of keratin 10 and involucrin [12]. These antiproliferative properties of $4 \mathrm{HR}$ have synergistic effects when it is used with conventional anticancer drugs such as cisplatin [13].

As 4HR can suppress the NF-kB pathway [11], it may also influence osteoclast activity. The NF-kB pathway is important in osteoclast activation [14]. If 4HR inhibits the NF-kB pathway during bone regeneration, more bone formation can be anticipated. Actually, hydroxyapatite (HA) coating with $4 \mathrm{HR}$ in a dental implant shows better bone formation than just HA coating 
without 4HR [15]. As osteoclasts are also a type of multinucleated cell, $4 \mathrm{HR}$ can suppress formation of multinucleated cells [16]. This action is helpful for the inhibition of the reaction to foreign bodies induced by silk materials and results in better bone formation [16]. Silk is a poorly degradable material when it is implanted in the body [17]. 4HR also accelerates degradation of silk graft materials [16, 17].

Collectively, xenografts treated with $4 \mathrm{HR}$ have been shown to suppress the reaction to foreign bodies and to promote rapid degradation of poorly biodegradable materials. The objective of this study was to evaluate xenograft degradation velocity upon treatment with $4 \mathrm{HR}$.

\section{Methods}

\section{Graft preparation}

The scapula of a cow was purchased from a local grocery. Using trephine bur (diameter $8.0 \mathrm{~mm}$ ), round bone grafts were cut at a thickness of $1.0 \mathrm{~mm}$. The control bone was placed into a conical tube containing a $10 \%$ ethanol solution, and the experimental bone was placed in a $10 \%$ ethanol and $3 \% 4 \mathrm{HR}$ solution. These tubes were placed on a rotating machine for $24 \mathrm{~h}$. Then, the grafts were placed in the drying oven for $8 \mathrm{~h}$. They were sterilized with ethylene oxide gas and stored at room temperature before usage. The weight of dried grafts was measured and the amount of $4 \mathrm{HR}$ incorporation into the experimental bone was between 10 to $15 \%$ by weight.

\section{X-ray diffraction, Fourier transform infrared absorbance spectra, and endotoxin test}

$\mathrm{X}$-ray diffraction (XRD) patterns of the samples were collected in the range of 10 to $60^{\circ}(2 \theta)$ using a diffractometer (PANalytical, X'Pert Pro MPD) with a $\mathrm{Cu}-\mathrm{K} \alpha$ $(\lambda=1.5418 \AA)$ radiation source. Fourier transform infrared (FT-IR) spectrum measurements were carried out using a Vertex 80 (Bruker Optics, Germany) spectrometer coupled with a Hyperion 3000 (Bruker Optics, Germany) microscope equipped with a germanium attenuated total reflectance objective lens $($ ATR $\times 20)$ and a liquid nitrogen-cooled mercury cadmium telluride detector.

An endotoxin test was performed using a commercial kit, and the subsequent procedure was in accord with the manufacturer's protocol.

\section{Antibacterial test}

Two oral pathogens (Streptococcus sanguinis, ATCC 10556, and Aggregatibacter actinomycetemcomitans, ATCC 33384) and Staphylococcus aureus (ATCC 502A) were used for antibacterial tests. The bacterial strains were cultured with brain heart infusion (BHI) (Becton, Dickinson and Company, Sparks, MD, USA) broth under aerobic conditions supplemented with $5 \% \mathrm{CO}_{2}$. $S$. aureus was also cultured under aerobic conditions.
The control disc and experimental disc were placed on the surface of blood agar plates (Hangang, Gunpo-si, Korea) for S. sanguinis and S. aureus and BHI plates for $A$. actinomycetemcomitans. For comparison, two different types of antibiotic discs (vancomycin and penicillin) were also used. The plates of $S$. sanguinis and A. actinomycetemcomitans were incubated at $37{ }^{\circ} \mathrm{C}$ aerobically supplemented with $5 \% \mathrm{CO}_{2}$ for 2 days. For $S$. aureus, the plates were incubated at $37^{\circ} \mathrm{C}$ aerobically for 1 day. The maximum diameter of the inhibition zone was observed.

\section{Scanning electron microscopic examination with EDX microanalysis and cellular attachment assay}

The specimens were coated with $0.7 \mathrm{~nm}$ of $\mathrm{OsO}_{4}(\mathrm{HPC}$ 1SW, Japan). Each specimen was observed using a scanning electron microscope (Hitachi, SU-70) and underwent EDX microanalysis (EDAX Genesis; Pv 77, EDAX, USA) to analyze the elements of the area of interest. The compositions of the elements were compared.

Murine macrophages from the Cell Bank (RAW264.7; Korean Cell Line Bank No. 40071) were grown on the control and experimental discs. The growth of the cell culture was stopped at $1 \mathrm{~h}$ after seeding by fixing the samples. All materials including raw materials were prepared for scanning electron microscopic examination. After immobilization of the samples on the plate, each sample was coated with gold and examined using a scanning electron microscope (H-800, Hitachi, Japan).

\section{Animal experiment}

This animal study was approved by IACUC (GWNU2014-14). Seventeen 12-week-old Sprague-Dawley rats with an average weight of $300 \mathrm{~g}$ were used for this experiment. A dental-trephine bur was used under copious saline solution irrigation to form a full-thickness calvarial defect. An 8-mm-diameter defect was created on the rat parietal bone, and the control graft or experimental graft was placed in the defect. The control group consisted of eight animals, and the experimental group included nine animals. After the grafting procedure, the pericranium and skin were sutured with 3-0 black silk. The animals were sacrificed 6 weeks after the operation.

\section{Histological analysis}

The calvarial samples were subjected to dehydration and embedding. The segments were embedded to show the sagittal sections in paraffin blocks. The paraffin blocks were sliced $(5 \mu \mathrm{m})$ and stained with hematoxylin and eosin. The detailed staining procedure followed the standard method in the manufacturer's manual. The selected sections were photographed with a digital camera (DP-73; Olympus, Tokyo, Japan). The images were analyzed with Sigma Scan Pro (SPSS, Chicago, IL). The ratio 
of the remaining graft was calculated based on the ratio of the remaining graft to the original size of the graft.

\section{Statistical analysis}

An independent sample $t$ test was used to compare the control and experimental groups in the animal study. The significance level was set at $P<0.05$.

\section{Results}

4HR-incorporated bovine bone had antibacterial properties

Figure 1a shows the XRD patterns of the bovine and 4HRtreated bovine samples. The bovine specimenpresents a typical diffraction pattern corresponding to an HA phase (International Center for Diffraction Data (ICDD), 003-0747), consisting of calcium hydroxide phosphate
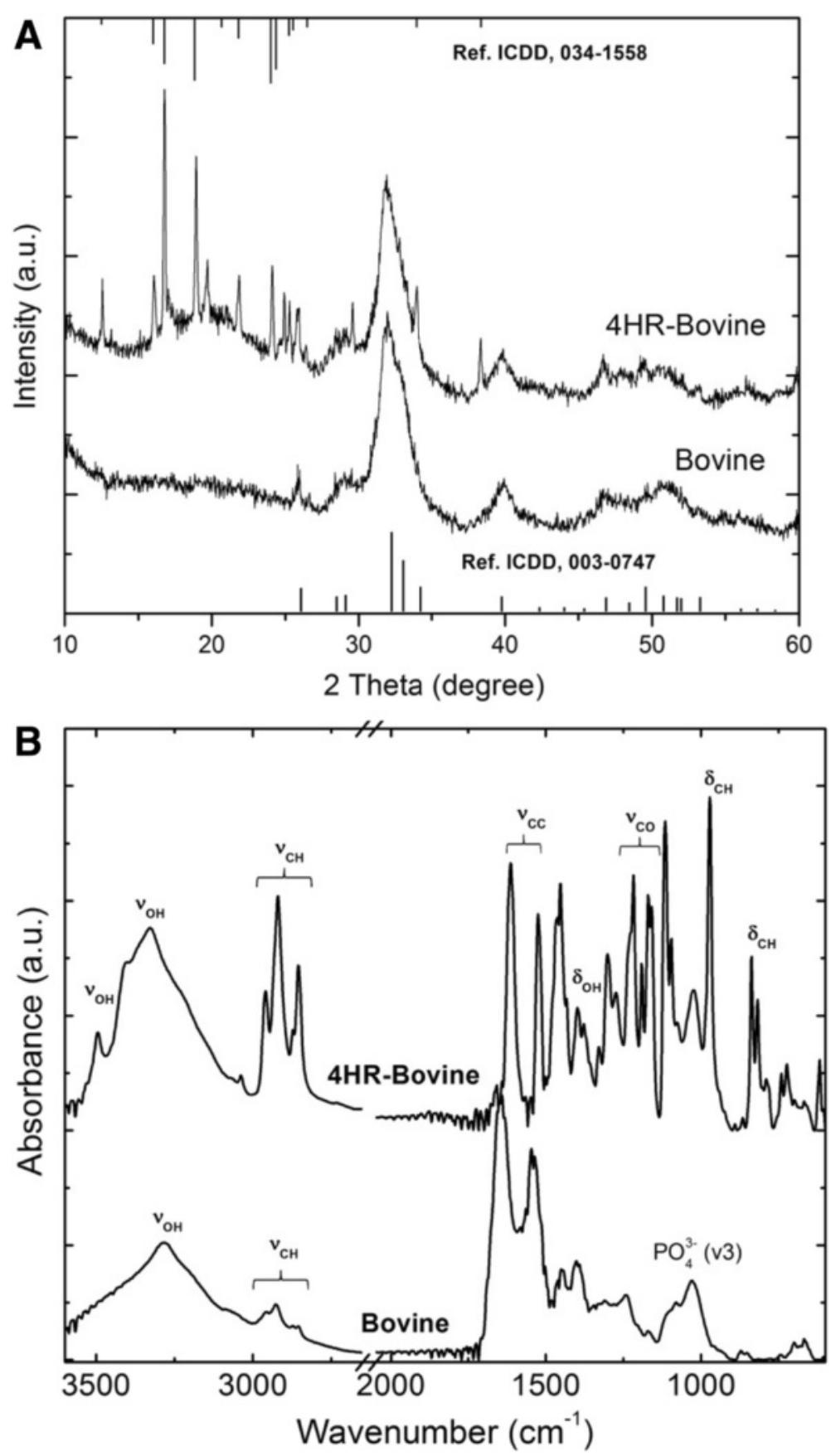

Fig. 1 a XRD patterns of the bovine and 4-hexylresorcinol (4-HR)-treated bovine samples. b FT-IR spectra 
components. The observed diffraction peaks were somewhat broadened, indicating low crystallinity. 4HR treatment does not change any diffractions of the bovine. Otherwise, additional narrow diffraction peaks were observed in the relatively low angle region, and the pattern was reasonably matched to the reference diffraction of
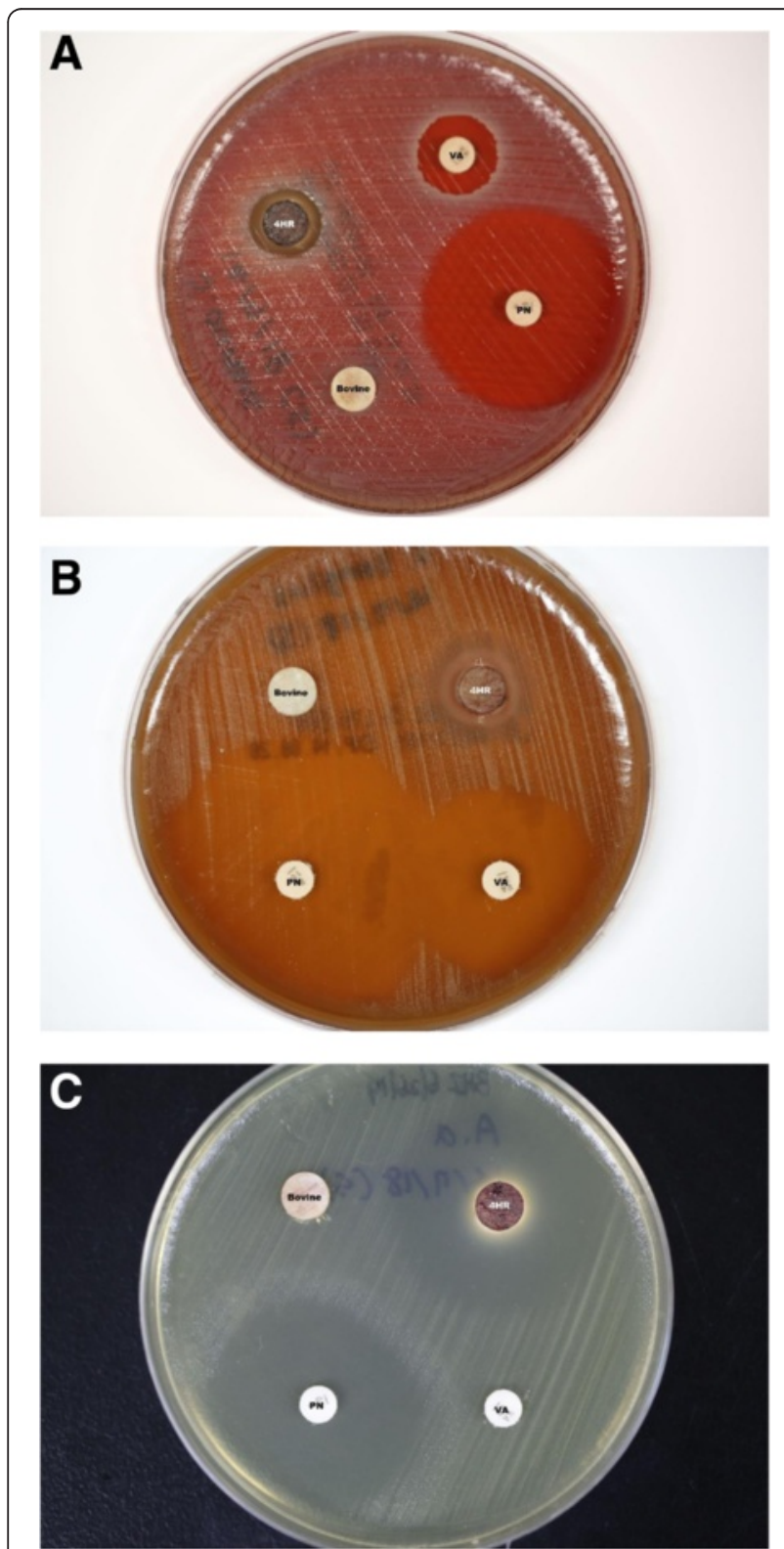

Fig. 2 Antibacterial test. a S. sanguinis, b $S$. aureus, and c A. actinomycetemcomitans (PN penicillin, VA vancomycin, 4HR 4-hexylresorcinol-incorporated bovine bone). The 4-hexylresorcinol-incorporated bovine bone disc inhibited the growth of all tested bacteria. Interestingly, vancomycin could not inhibit the growth of $A$. actinomycetemcomitans, while the 4-hexylresorcinol-incorporated bovine bone disc showed a similar inhibition level to the penicillin disc (c)
4HR (ICDD, 034-1558). The narrow diffraction peaks imply high crystalline characteristics.

As seen in the FT-IR spectra, the bovine sample shows several vibrational absorptions: an $\mathrm{OH}$ vibration at $3250 \mathrm{~cm}^{-1}$ and a $\mathrm{PO}_{4}^{3-}$ vibration at $1026 \mathrm{~cm}^{-1}$ (Fig. 1b). The characteristic vibrations of aliphatic hydrocarbons at $2800 \sim 3000 \mathrm{~cm}^{-1}$ and the vibrational absorptions at 1200 $\sim 1700 \mathrm{~cm}^{-1}$ are attributed to organic moieties in the bovine samples. The $4 \mathrm{HR}$-treated bovine sample clearly shows distinctive infrared absorptions corresponding to $4 \mathrm{HR}[18,19]$. The $\mathrm{OH}$ and aliphatic hydrocarbon peaks are also strengthened in the region of 2800 to $3600 \mathrm{~cm}^{-1}$. The 1614 and $1525 \mathrm{~cm}^{-1}$ peaks are attributed to aromatic ring $C-C$ stretching. The 1217, 1192, and $1171 \mathrm{~cm}^{-1}$ absorptions are attributed to $\mathrm{C}-\mathrm{O}$ stretching. The vibrational absorption at $972 \mathrm{~cm}^{-1}$ is attributed to $\mathrm{CH}_{2}$ wagging, and the several absorption peaks at $780 \sim$ $840 \mathrm{~cm}^{-1}$ can be assigned to aromatic $\mathrm{C}-\mathrm{H}$ bending [19] A subsequent endotoxin assay yielded results of $0.04 \mathrm{EU} / \mathrm{ml}$ for the control disc and $0.01 \mathrm{EU} / \mathrm{ml}$ for
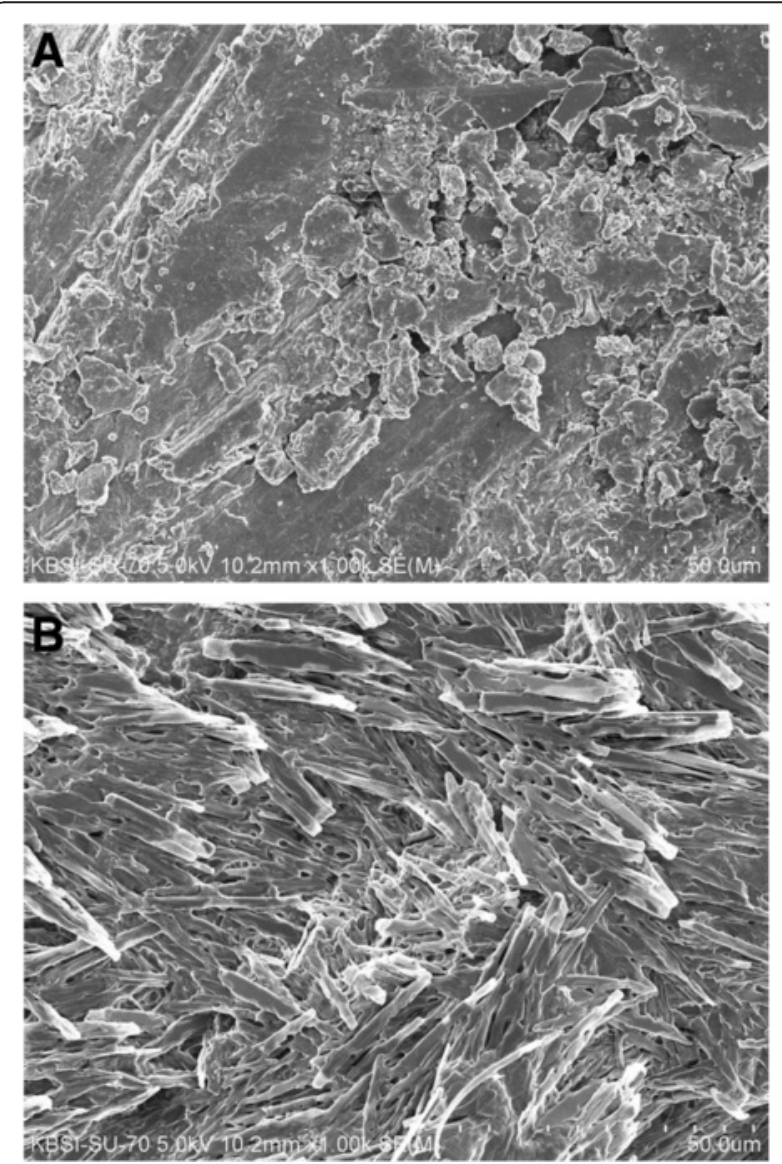

Fig. 3 SEM analysis of the graft. The surface of the bovine bone was generally flat with hydroxyapatite crystal and organic material (a). However, the surface of the 4-hexylresorcinol-incorporated bovine bone showed multiple needle-like crystals (b) 
Table 1 Composition of elements evaluated by EDX microanalysis

\begin{tabular}{ccc}
\hline Element & Bovine bone & 4HR treated bovine bone \\
\hline $\mathrm{C}$ & $48.73 \pm 2.90$ & $62.43 \pm 0.46$ \\
$\mathrm{O}$ & $31.13 \pm 2.05$ & $27.29 \pm 0.23$ \\
$\mathrm{Na}$ & $0.42 \pm 0.03$ & Not detected \\
$\mathrm{Mg}$ & $0.29 \pm 0.05$ & Not detected \\
$\mathrm{Ca}$ & $9.51 \pm 0.61$ & $6.40 \pm 0.19$ \\
$\mathrm{P}$ & $5.92 \pm 0.38$ & $3.88 \pm 0.09$ \\
\hline
\end{tabular}

the experimental disc. These values were below the level of endotoxin contamination $(<0.3 \mathrm{EU} / \mathrm{ml})$.

The experimental disc showed a clear bacterial inhibitory zone (Fig. 2). However, the control disc did not have any inhibitory zones. The experimental disc inhibited the growth of all tested bacteria. Interestingly, vancomycin could not inhibit the growth of A. actinomycetemcomitans, while the experimental group showed similar inhibition levels for the penicillin disc.

In the SEM analysis, the experimental disc showed needle-like crystals on its surface (Fig. 3). Resorcinol is a needle-like crystal that becomes pink upon exposure to light and air [20]. EDX microanalysis demonstrated that the composition of carbon was increased compared to the untreated control (Table 1). The calcium and phosphate contents were also decreased after the $4 \mathrm{HR}$ treatment. RAW264.7 cells on the control disc were spherical and did not spread at $1 \mathrm{~h}$ after seeding (Fig. 4). However, RAW264.7 cells were well spread on the 4HRtreated bovine disc. Interestingly, numerous submicronsized processes were observed on the surface of the macrophage.

\section{Rapid degradation of 4HR-incorporated bovine bone graft}

Serial radiography demonstrated rapid degradation in the experimental group (Fig. 5). Six of the nine grafts in the experimental group showed complete degradation at 6 weeks after surgery. The grafts started to disappear at 3 weeks after surgery. However, all grafts were observed in the control group, and there was no significant change in size until 6 weeks. When the amount of residual graft was compared, the difference between the groups was statistically significant (Fig. 6; $P=0.003$ ). Two animals that received 4HR-incorporated grafts showed heavy seroma formation on the grafted site. One was drained spontaneously, but the other was observed until 6 weeks after surgery.

Histological exams are shown in Fig. 7. The untreated control was encapsulated by fibrotic tissue (Fig. 7a). The sample of the complete degradation of the graft demonstrated an almost complete disappearance of the implant
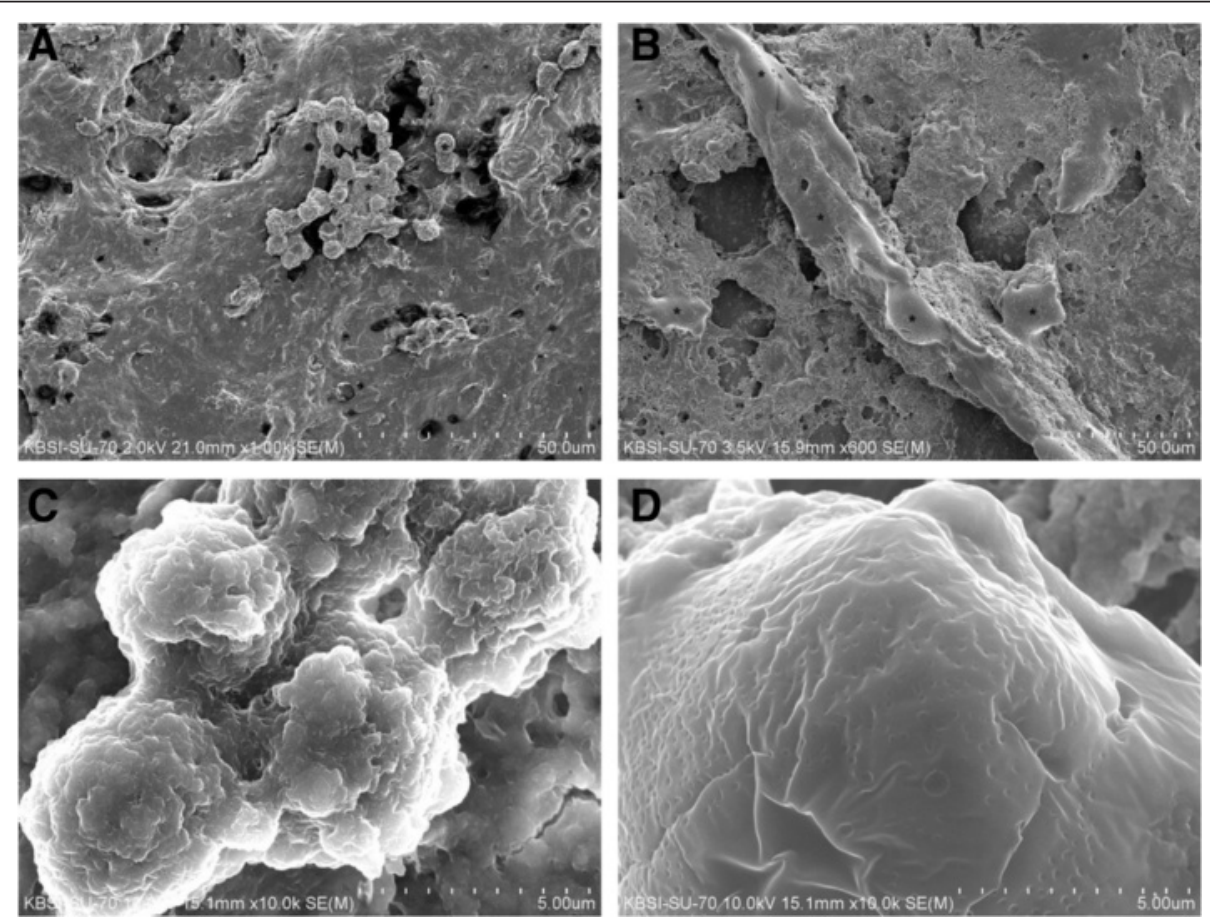

Fig. 4 Cellular attachment test. Small, round cells (asterisk) were sporadically attached on the surface of bovine bone (a). Cellular spreading (asterisk) was frequently observed, and multiple round projections on the cellular surface were noticed in the 4-hexylresorcinol-incorporated bovine bone group (b). High magnification view demonstrated small cells conglomerated each other in the bovine bone group (c). Large cells with multiple round projections were found in the 4-hexylresorcinol-incorporated bovine bone group 

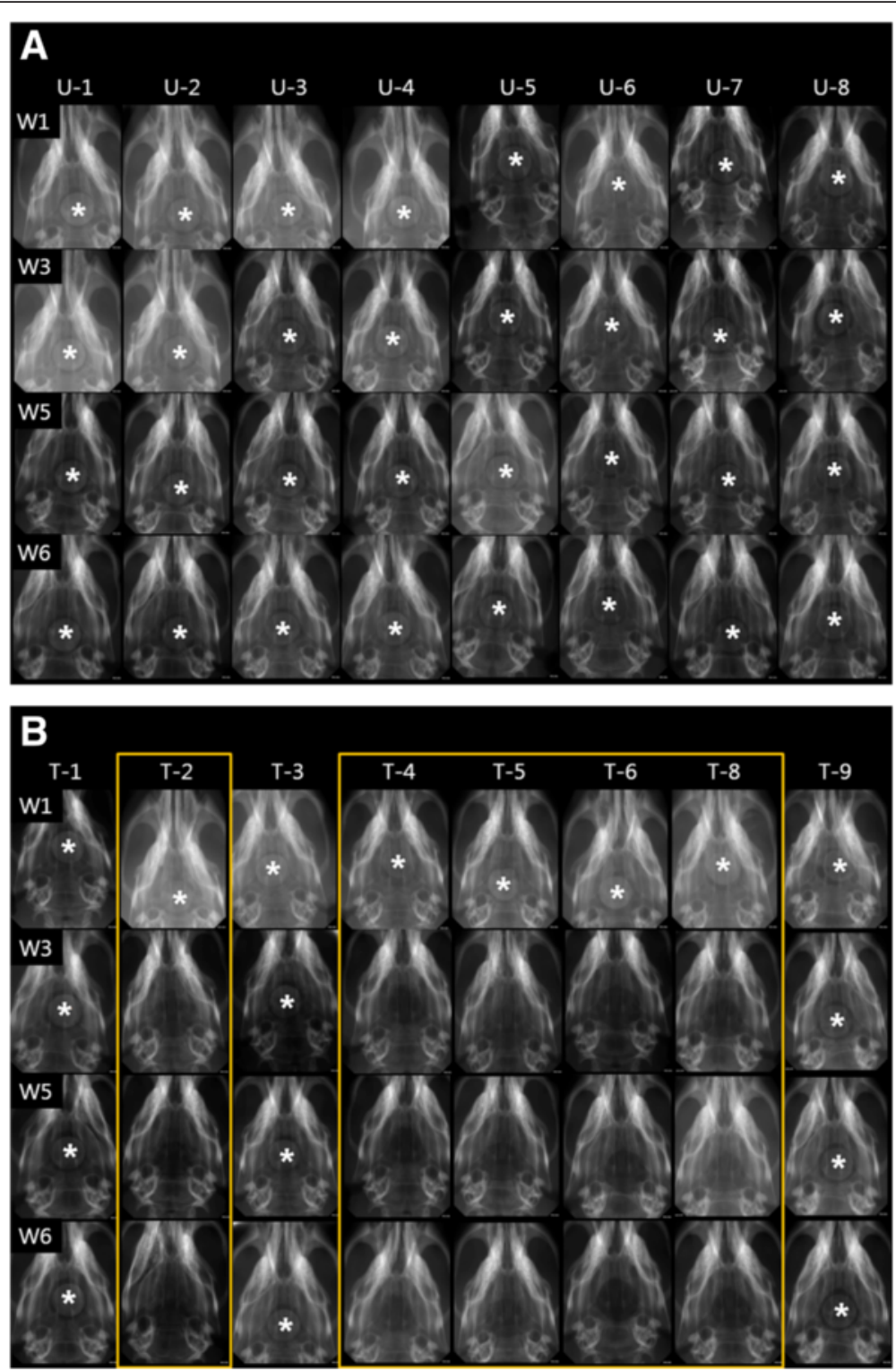

Fig. 5 Serial radiograph. The radiograph was taken 1 (W1), 3 (W3), 5 (W5), and 6 (W6) weeks after operation. a The animals received bovine bone implants (asterisk). All implants were present until 6 weeks after operation. b The animals received 4-hexylresorcinol-incorporated bovine bone implants (asterisk). Five implants were not observed from 3 weeks after operation (boxed by yellow line)

with a well-developed vascular channel in the bone defect (Fig. 7b). Some samples from the 4HR-treated group showed minimal degradation of the implant (Fig. 7c). Interestingly, some samples from the untreated groups showed that the newly regenerated bone was in contact with the graft (Fig. 7d). In the experimental group, there were a few regenerated bones in the defect (Fig. 7e). Loose fibrotic tissue occupied the area of grafting. Under high magnification, we observed that multinucleated cells encompassed the residual graft (Fig. 7e). There was a rich vascular network around the residual graft. There were few multinucleated cells. The samples with less degradation showed no difference in gross view compared to those in the control group. Under high magnification, local resorption with reparative bone regeneration was observed (Fig. 7f). However, multinucleated cells were not observed.

\section{Discussion}

In this study, bovine bone obtained from a local grocery was used for the repair of rat calvarial defect after simple processing. 4HR-treated bovine bone had antibacterial properties, and RAW264.7 cells were well attached to the surface of the 4HR-treated bovine bone. 4HR-treated bovine bone had a higher degradation rate than the untreated control. However, its degradation velocity was 


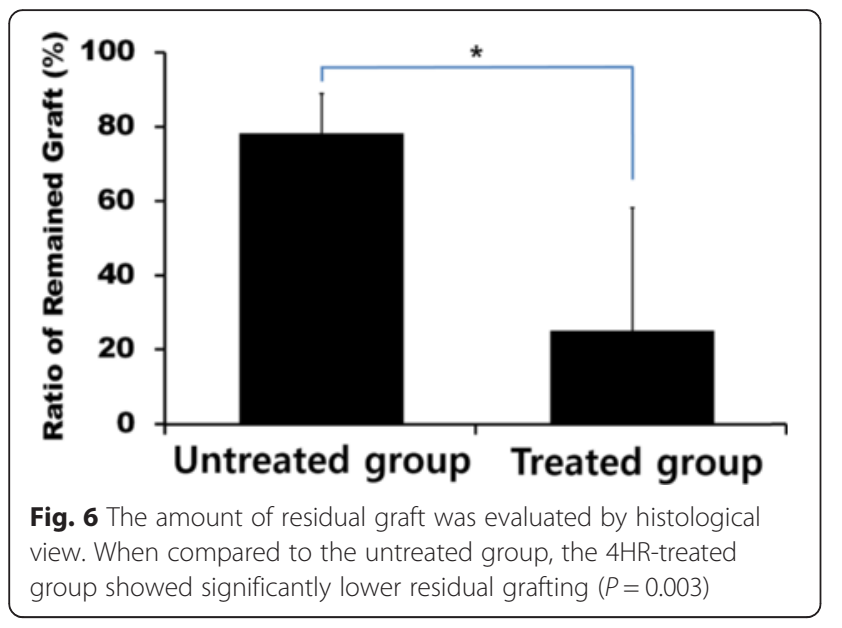

too rapid and did not contribute to new bone regeneration.

4HR is a family of hydroxyl phenols [6]. 4HR has two $-\mathrm{OH}$ groups. $\mathrm{A} \mathrm{H}^{+}$ion can be released from $-\mathrm{OH}$ groups of the benzene ring, and the $4 \mathrm{HR}$ has acidic properties [20]. Therefore, the concentration of $4 \mathrm{HR}$ in the bone graft should be carefully monitored. If the concentration of $4 \mathrm{HR}$ is too high and is used for HAbased bone graft materials, $\mathrm{H}^{+}$ions released from the graft would decrease the $\mathrm{pH}$ locally and result in massive loss of calcium from the graft. Although all prepared graft materials came from the same conical tube, some grafts might not have been exposed to $4 \mathrm{HR}$. As a result, there might be a variation in the $4 \mathrm{HR}$ concentration among grafts. Based on the weight change of the graft, the $4 \mathrm{HR}$ concentration of each graft was expected to range from 10 to $15 \%$ by weight. HA incorporating gluconic acid is almost completely degraded 2 weeks after surgery [4]. The amount of acid and the release pattern would influence the overall degradation velocity of HA [4]. In a previous study, $3 \%$ wt $4 \mathrm{HR}$ in HA or silk was not shown to accelerate graft loss [16]. Therefore, lower concentration of $4 \mathrm{HR}$ should be used for bovine bone graft in future study.

4HR can induce cellular apoptosis dependent on its concentration. In the case of epithelial cancer, the apoptosis-inducing concentration is much lower than that of the normal dermal fibroblast [12]. As the 4HR concentrations of grafts were relatively higher than those of a previous study [16], high concentrations of 4HR might induce apoptosis responsible for graft degradation in some cases. Sintered bovine bone graft and synthetic HA are biodegraded by osteoclasts [21] or macrophages [22]. The exact concentration of $4 \mathrm{HR}$ required for apoptosis in these cells is yet to be determined. The bovine bone used for the implant may have been treated by heat. However, chemically treated bovine bone has better mechanical properties than heat-treated bone [23]. As $4 \mathrm{HR}$ treatment is a chemical treatment, it would not influence the bone's original mechanical property.
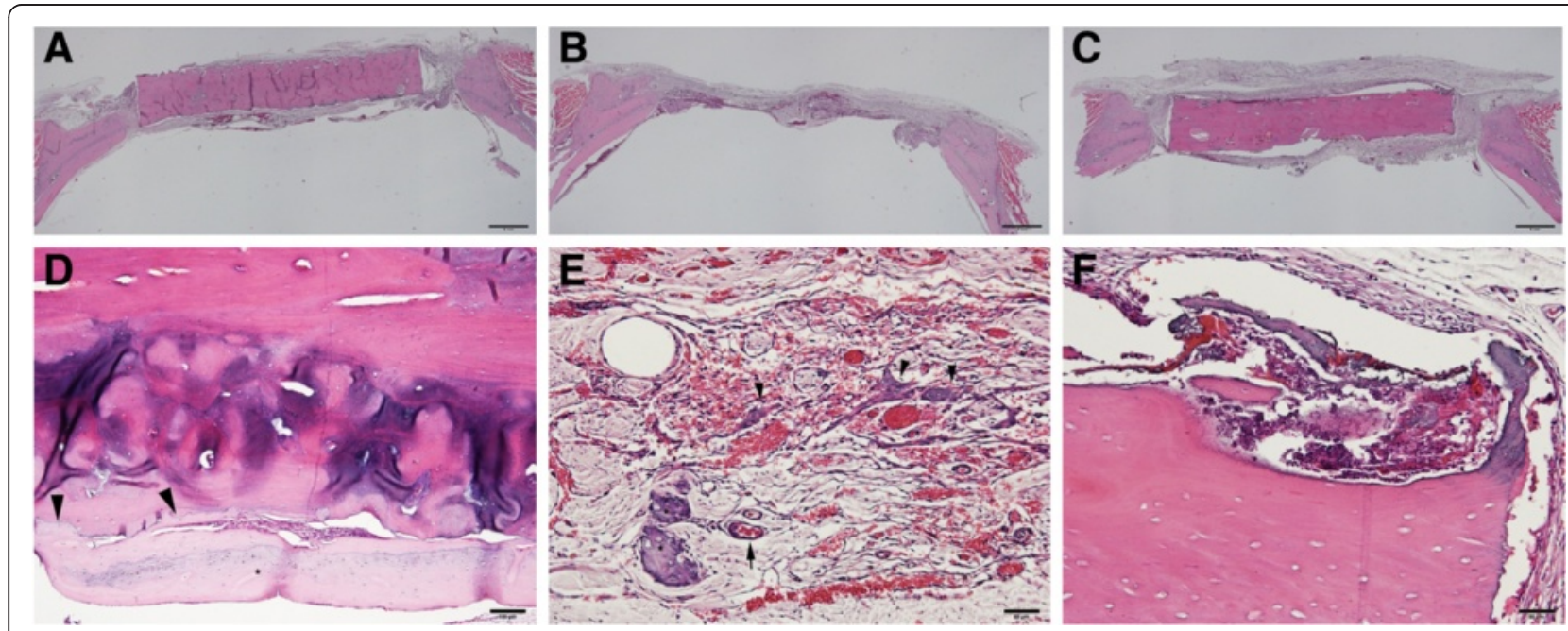

Fig. 7 Histological exam. a The bovine bone implant was encapsulated by a fibrotic capsule, and no sign of degradation was observed. b The animal that received 4-hexylresorcinol-incorporated bovine bone implants showed little residual grafting and still experienced a large bony defect. New bone formation was observed only in the cutting edge of the calvarial bone. $\mathbf{c}$ Another animal bovine bone implant incorporated with 4-hexylresorcinol showed focal degradation of the graft. Most grafts still occupied the bony defect. $\mathbf{d}$ New bone regeneration (asterisk) over the bovine implant was observed in some animals that received a bovine bone implant. The regenerated bone directly contacted with the implant (arrow heads). e High magnification view of (b). Residual graft was stained with violet color (asterisk), and multinucleated giant cells (arrow heads) were observed. Highly developed vascular channels were also observed. Interestingly, some giant cells appeared to transform into endothelial cells (arrow head). $\mathbf{f}$ High magnification view of (c). Focal dissolution of implants with reparative calcification was observed 
In this study, the control group showed new bone deposition bordering the graft (Fig. 7d). Mixed bovine bone grafted in the rat calvarial defect was not completely degraded at 9 months, while new bone formation was observed in the defect border [24]. There was no inflammation around the graft in the control group (Fig. 7a, d). As the control group was only treated with $24 \mathrm{~h}$ ethanol washing, using a graft material process that originates from bovine bone may be considered in the future. The graft materials in this study were sterilized by ethylene oxide. As demonstrated in the EDX analysis results, many organic components may remain in the bovine bone. Bio-Oss also has residual proteins [25]. The ethylene oxide sterilization does not reduce osteoinductivity of bone morphogenetic proteins [26]. Therefore, bone morphogenetic proteins in the bovine bone would not be destroyed by ethylene oxide. Only the concentration of $4 \mathrm{HR}$ in the graft appeared to be unknown in this study. The optimal 4HR concentration for bone graft should be determined in future studies.

\section{Conclusions}

In this study, 4HR was successfully incorporated into bovine bone, and 4HR-incorporated bovine bone had antibacterial property. The in vivo experiment demonstrated that 4HR-incorporated bovine bone showed more rapid degradation than untreated bovine bone. However, 4HRincorporated bovine bone graft did not show elevated new bone formation.

\section{Acknowledgements \\ The authors thank Hyo-Seon Kim and Min-Keun Kim for their help in the experiments. This work was carried out with the support of "Cooperative Research Program for Agriculture Science and Technology Development (Project No. PJ01121404)", Rural Development Administration, Republic of Korea.}

\section{Authors' contributions}

KYJ and NJE did most of the experiment and KSG designed this experiment. LMJ and CWS did XRD and FT-IR analysis. LSY did antibacterial test. KSG, CWS, and LSY wrote the manuscript and did critical review on the experimental process. All authors read and approved the final manuscript.

\section{Competing interests}

The authors declare that they have no competing interests.

\section{Author details}

'Department of Oral Microbiology, College of Dentistry, Gangneung-Wonju National University, 7 Jukhyun-gil, Gangneung 25457, Republic of Korea. ${ }^{2}$ Gangneung Center, Korea Basic Science Institute, Gangneung 25457, Republic of Korea. ${ }^{3}$ Analysis Research Division, Daegu Center, Korea Basic Science Institute, Daegu 41566, Republic of Korea.

Received: 24 May 2016 Accepted: 5 July 2016

Published online: 05 August 2016

\section{References}

1. Cha HS, Kim JW, Hwang JH, Ahn KM (2016) Frequency of bone graft in implant surgery. Maxillofac Plast Reconstr Surg 38(1):19

2. Kim ES, Lee IK, Kang JY, Lee EY (2015) Various autogenous fresh demineralized tooth forms for alveolar socket preservation in anterior tooth extraction sites: a series of 4 cases. Maxillofac Plast Reconstr Surg 37(1):27
3. Kassim B, Ivanovski S, Mattheos N (2014) Current perspectives on the role of ridge (socket) preservation procedures in dental implant treatment in the aesthetic zone. Aust Dent J 59(1):48-56

4. Sariibrahimoglu $K$, An J, van Oirschot BA, Nijhuis AW, Eman RM, Alblas J, Wolke JG, van den Beucken JJ, Leeuwenburgh SC, Jansen JA (2014) Tuning the degradation rate of calcium phosphate cements by incorporating mixtures of polylactic-co-glycolic acid microspheres and glucono-deltalactone microparticles. Tissue Eng Part A 20(21-22):2870-82

5. Ding X, Takahata M, Akazawa T, Iwasaki N, Abe Y, Komatsu M, Murata M, Ito M, Abumi K, Minami A (2011) Improved bioabsorbability of synthetic hydroxyapatite through partial dissolution-precipitation of its surface. J Mater Sci Mater Med 22(5):1247-55

6. Kozubek A, Tyman JH (1999) Resorcinolic lipids, the natural non-isoprenoid phenolic amphiphiles and their biological activity. Chem Rev 99(1):1-26

7. Evans RT, Baker PJ, Coburn RA, Fischman SL, Genco RJ (1977) In vitro antiplaque effects of antiseptic phenols. J Periodontol 48(3):156-62

8. Thepnuan R, Benjakul S, Visessanguan W (2008) Effect of pyrophosphate and 4-hexylresorcinol pretreatment on quality of refrigerated white shrimp (Litopenaeus vannamei) kept under modified atmosphere packaging. J Food Sci 73(3):S124-33

9. McNally D, Shephard A, Field E (2012) Randomised, double-blind, placebo-controlled study of a single dose of an amylmetacresol/ 2,4-dichlorobenzyl alcohol plus lidocaine lozenge or a hexylresorcinol lozenge for the treatment of acute sore throat due to upper respiratory tract infection. J Pharm Pharm Sci 15(2):281-94

10. Kim SG, Choi JY (2013) 4-hexylresorcinol exerts antitumor effects via suppression of calcium oscillation and its antitumor effects are inhibited by calcium channel blockers. Oncol Rep 29(5):1835-40

11. Kim SG, Lee SW, Park YW, Jeong JH, Choi JY (2011) 4-hexylresorcinol inhibits $\mathrm{NF}-\mathrm{kB}$ phosphorylation and has a synergistic effect with cisplatin in KB cells. Oncol Rep 26(6):1527-32

12. Kim SG, Kim AS, Jeong JH, Choi JY, Kweon H (2012) 4-hexylresorcinol stimulates the differentiation of SCC-9 cells through the suppression of E2F2, E2F3 and Sp3 expression and the promotion of Sp1 expression. Oncol Rep 28(2):677-81

13. Lee SW, Kim SG, Park YW, Kweon H, Kim JY, Rotaru H (2013) Cisplatin and 4hexylresorcinol synergise to decrease metastasis and increase survival rate in an oral mucosal melanoma xenograft model: a preliminary study. Tumour Biol 34(3):1595-603

14. Abu-Amer Y (2013) NF-kB signaling and bone resorption. Osteoporos Int 24(9):2377-86

15. Kim SG, Hahn BD, Park DS, Lee YC, Choi EJ, Chae WS, Baek DH, Choi JY (2011) Aerosol deposition of hydroxyapatite and 4-hexylresorcinol coatings on titanium alloys for dental implants. J Oral Maxillofac Surg 69(11):e354-63

16. Kweon H, Kim SG, Choi JY (2014) Inhibition of foreign body giant cell formation by 4-hexylresorcinol through suppression of diacylglycerol kinase delta gene expression. Biomaterials 35(30):8576-84

17. Lee SW, Um IC, Kim SG, Cha MS (2015) Evaluation of bone formation and membrane degradation in guided bone regeneration using a 4hexylresorcinol-incorporated silk fabric membrane. Maxillofac Plast Reconstr Surg 37:32

18. Carver CD (1982) The Coblentz Society Desk Book of Infrared Spectra, 2nd edn. The Coblentz Society, Kirkwood, MO

19. Yang WG, Ha JH, Kim SG, Chae WS (2016) Spectroscopic determination of alkyl resorcinol concentration in hydroxyapatite composite. J Anal Sci Tech 7:9

20. Durairaj RB (2005) Resorcinol: Chemistry, Technology and Applications. Springer, Leipzig

21. Rumpel E, Wolf E, Kauschke E, Bienengräber V, Bayerlein T, Gedrange T, Proff $P$ (2006) The biodegradation of hydroxyapatite bone graft substitutes in vivo. Folia Morphol 65(1):43-8

22. Xia ZD, Zhu TB, Du JY, Zheng QX, Wang L, Li SP, Chang CY, Fang SY I(1994) Macrophages in degradation of collagen/hydroxylapatite (CHA), beta-tricalcium phosphate ceramics (TCP) artificial bone graft. An in vivo study. Chin Med J 107(11):845-9

23. Lee Kl, Lee JS, Lee KS, Jung HH, Ahn CM, Kim YS, Shim YB, Jang JW (2015) Mechanical-chemical analyses and sub-chronic systemic toxicity of chemical treated organic bovine bone. Regul Toxicol Pharmacol 73(3):747-53

24. Accorsi-Mendonça T, Zambuzzi WF, Bramante CM, Cestari TM, Taga R, Sader M, de Almeida Soares GD, Granjeiro JM (2011) Biological monitoring of a xenomaterial for grafting: an evaluation in critical-size calvarial defects. J Mater Sci Mater Med 22(4):997-1004 
25. Taylor JC, Cuff SE, Leger JP, Morra A, Anderson Gl (2002) In vitro osteoclast resorption of bone substitute biomaterials used for implant site augmentation: a pilot study. Int J Oral Maxillofac Implants 17(3):321-30

26. Ijiri S, Yamamuro T, Nakamura T, Kotani S, Notoya K (1994) Effect of sterilization on bone morphogenetic protein. J Orthop Res 12(5):628-36

\section{Submit your manuscript to a SpringerOpen ${ }^{\circ}$ journal and benefit from:}

- Convenient online submission

- Rigorous peer review

- Immediate publication on acceptance

- Open access: articles freely available online

- High visibility within the field

- Retaining the copyright to your article

Submit your next manuscript at $>$ springeropen.com 